
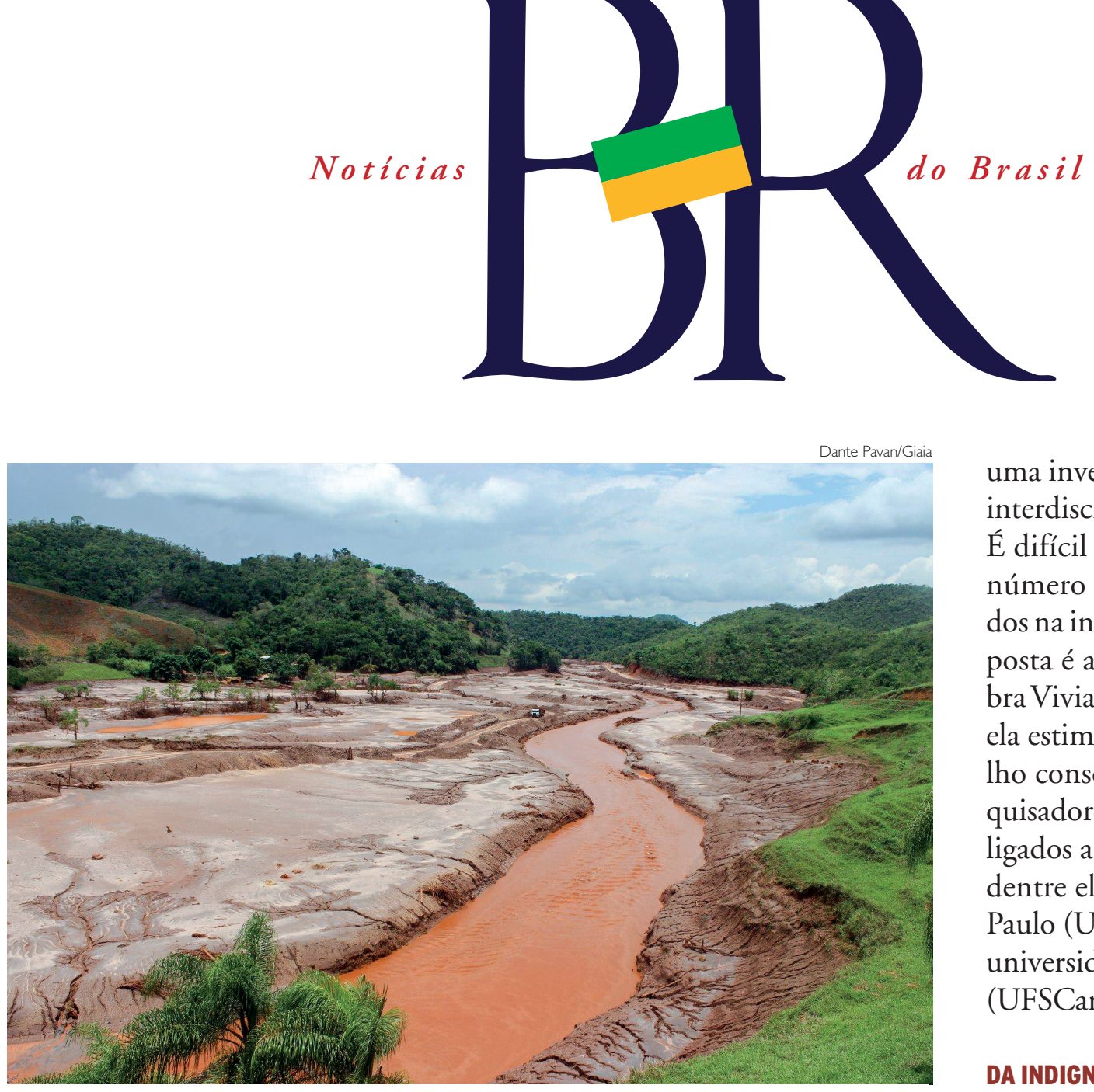

Camada de rejeitos com $40 \mathrm{~cm}$ de espessura depositada até $5 \mathrm{~m}$ acima do Rio Gualaxo em Monsenhor Horta (MG) sofre erosão e é levado pela chuva para dentro do rio

MARIANA

\title{
Desastre ambiental incentiva monitoramento alternativo de ciência aberta
}

Fazer uma análise independente dos impactos ambientais do desastre em Mariana, Minas Gerais, esse é o objetivo do Grupo Independente de Avaliação do Impacto Ambiental (Giaia), uma proposta dentro do conceito de ciência aberta. "Todos os resultados são disponibilizados em tempo real. Assim, toda a sociedade colabora na discussão. Os nossos resultados geram mais perguntas que respostas, mas é exatamente assim o caminho científico", explica a bióloga e pesquisadora da Universidade Federal de São Paulo (Unifesp), Viviane Schuch, uma das coordenadoras do Giaia. Os resultados parciais do trabalho do grupo podem ser acessados no site criado pelo grupo (http://giaia.eco.br). Para facilitar a disseminação dos materiais nas comunidades internacionais, todos os documentos e textos foram traduzidos para o inglês. "Os nossos resultados são preliminares e pontuais, foram gerados a partir de uma investigação científica ampla e interdisciplinar", conta a bióloga.

É difícil contabilizar exatamente o número de colaboradores envolvidos na iniciativa, uma vez que a proposta é aberta e participativa, lembra Viviane, e, portanto, fluida. Mas ela estima que nos grupos de trabalho consolidados já sejam 100 pesquisadores diretamente envolvidos, ligados a várias instituições do país, dentre elas as universidades de São Paulo (USP) e de Brasília (UnB), as universidades federais de São Carlos (UFSCar) e de Alagoas (Ufal).

DA INDIGNAÇÃO PARA AÇÃO Ao contrário das análises sobre a presença de metais pesados feitas por órgãos do governo como o Serviço Geológico do Brasil (CPRM) e Agência Nacional das Águas (ANA), os resultados parciais apurados e disponibilizados pelo grupo apontam índices de manganês e arsênio acima do preconizado pela legislação do Conselho Nacional do Meio Ambiente (Conama) 357 que dispóe sobre a classificação dos corpos de água e diretrizes ambientais para o seu enquadramento, bem como estabelece as condições e padrões de lançamento de efluentes. Nas mediçôes feitas em dezembro em Governador Valadares, por exemplo, a concentração de arsênio estava quatro vezes acima do permitido. Os parâmetros alumínio e ferro dissolvido, selênio total, cádmio total, lítio total, ní- 
quel total e zinco total estavam em conformidade com a legislação. Já análises físico-químicas do Rio Doce e afluentes sob influência dos rejeitos provenientes no rompimento da barragem de Fundão concluíram elevada turbidez da água, causada pela grande quantidade de partículas em suspensão. A turbidez limita a penetração de luz usada pelas algas para fotossíntese, o que afeta a cadeia alimentar.

Os trabalhos realizados atéagora contaram com voluntários das comunidades afetadas pelo desastre. "Dentro da nossa proposta científica cidadã, toda a sociedade, principalmente a diretamente atingida pelo desastre, pode participar com depoimentos, coleta de dados e amostras, discussão e multiplicação dos resultados e economia solidária", afirma Viviane. "O envolvimento da comunidade nas atividades científicas é fundamental para expandir a nossa capacidade de coleta de dados; ampliar, disseminar e valorizar o conhecimento científico; valorizar e empoderar o cidadão, além de ampliar o pensamento crítico e gerar insumos políticos para um possível debate posterior das consequências do desastre", enfatiza.

Para Wilson Jardim, químico ambiental da Universidade Estadual de Campinas (Unicamp) a iniciativa é um exercício de cidadania que deve servir de exemplo. "No entanto, é importante que o pessoal engajado nestas atividades, as quais exigem um mínimo de conhecimento técnico, seja devidamente treinado. O grande erro de um leigo é que ele 'percebe e avalia' o ambiente de modo heurístico, subjetivo, o que muitas vezes não condiz com a realidade". Para padronizar as coletas, o site do Giaia disponibiliza protocolos para recolher amostras para análises de microrganismos do solo, análises isotópicas e para testes de ecotoxicidade.

FINANCIAMENTO Numa primeira fase de crowdfunding (verba coletiva captada via internet), o Giaia arrecadou R\$90 mil. Segundo Viviane Schuch, o dinheiro será utilizado principalmente para financiar as expediçốes de coleta de amostras e a remessa das mesmas para os pesquisadores associados. Certamente esse é um dos grandes desafios para a continuidade do trabalho do grupo porque, a despeito de contar com mão de obra voluntária, a pesquisa científica envolve custos. Para se ter uma ideia de valores, em 24 de maio de 2010, logo após o derramamento de óleo da Deepwater Horizon Oil, no Golfo do México, a British Petroleum (BP) assumiu o compromisso de repassar até US\$ 500 milhôes no período de 10 anos para financiar um programa de investigação independente para estudar o impacto ambiental do vazamento de óleo no Golfo do México. Os recursos têm sido repassados para instituições co- mo a Louisiana State University, Instituto de Oceanografia da Flórida e para o Instituto do Golfo Norte, um consórcio liderado pela Mississippi State University. Os resultados das pesquisas são divulgados na internet no âmbito da Iniciativa de Pesquisa para o Golfo do México (GoMRI). O Giaia teve uma origem bem diferente do GoMRI. O grupo nasceu a partir da mobilização de um grupo de biólogos da USP no Facebook, pouco tempo depois do rompimento das barragens de Fundão e Santarém, no dia 5 de novembro de 2015 . Nesse dia a lama dos reservatórios invadiu o distrito de Bento Rodrigues, na cidade histórica de Mariana (MG), causou ao menos 17 mortes e levou milhões de metros cúbicos de rejeitos da extração de minérios de ferro da mineradora Samarco a percorrerem cerca de 650 quilômetros, na bacia do rio Doce, até chegar ao mar, no Espírito Santo. Diante de informações conflitantes o grupo passou a ser uma opção para gerar informações de forma independente. Até o momento, o Giaia firmou parcerias com o Ministério Público e outras instituiçóes e agora se concentra em sua estruturação, consolidação dos grupos de trabalho e criação de um ambiente de colaboração científica-cidadã. "O Giaia é um enorme desafio", finaliza Viviane.

Patrícia Mariuzzo Germana Barata 